\title{
Por mais fortes que possam ser os teus anseios, você não pode segurar a água*
}

Fernanda Oliveira Matos (UCHILE)**
https://orcid.org/0000-0003-4278-2058

Crescer na esperança do aquém e do além

Do continente e da pele de alguém

Lutar é crescer no além e no aquém

Afirmando a liberdade da raça amém

Abdias do Nascimento

Por mais fortes que possam ser os teus anseios, você não pode segurar a água narra a trajetória literária do escritor Bruno Caldeira. Numa busca incessante de construir sua identidade, o protagonista tece uma colcha de retalhos na qual podemos examinar a manifestação de distintas marcas de exclusão social.

Com uma linguagem poética, visceral e envolvente o livro apresenta os poemas que o autor escreveu desde a adolescência e nos conta com primor suas experiências de vida. Do amor tão buscado à discriminação sofrida que atravessa sua existência; das vivências que revelam também um retrato da

* O presente trabalho está vinculado ao projeto ANID+PAI-Convocatoria nacional subvención a la instalación en la academia, Convocatoria 2018, Folio 77180056, coordenado pela Dra. Daiana Nascimento dos Santos no Centro de Estudios Avanzados, Universidad de Playa Ancha, Chile.

** Mestre em Literatura pela Universidad de Chile. Atualmente é professora de Português como Língua Estrangeira (PLE) no Centro Cultural Brasil - Chile, órgão pertencente à Embaixada do Brasil em Santiago. Lattes: http://lattes.cnpq. br/3784840264800376. E-mail: fernanda.oliveira@ug.uchile.cl sociedade atual no contexto da pandemia do covid-2019, do racismo e da homofobia. Além de evidenciar a dificuldade de um autor negro publicar seus escritos e ser reconhecido.

0 autor comenta em uma entrevista ao jornal Acidade, de sua cidade natal, Araraquara, que este livro representa o fechamento de um ciclo no qual ele precisava expor sua realidade para que outras pessoas também se identificassem com as dificuldades que ele passou, como, o racismo:

Sofri racismo por conta da minha poesia, de falar da questão racial abertamente e também sofri censura. Pleiteei com duas outras editoras e os editores pediram pra mudar o conteúdo do livro, que não seria um conteúdo vendido. Aí posteriormente encontrei uma editora que topasse sem que precisasse mudar nenhuma virgula e pudesse me expressar como eu gostaria. (2020, s/p).

Em relação ao racismo, no poema Neguinho, o autor denuncia por meio dos versos: “...ô nariz largo cê num tem o perfil da vaga/ as lágrimas vêm/ neguinho o que ocorre?/e depois vai falar que nois somos todos iguais" (p.12); chamando atenção à impossibilidade de ascensão social e a invisibilidade do negro por não ter o perfil socialmente aceito e, ademais, mostra a hipocrisia do discurso que "somos todos iguais" que tanto camufla o racismo. Tais características típicas de países marcados por um processo de coloni- 
zação baseado essencialmente no racismo, como é o caso do Brasil.

Seguindo as ideias de Santos e Pereira (2020), em uma reflexão sobre a epígrafe "Eu não consigo respirar", é necessário refletir sobre as consequências da escravidão na comunidade afrodescendente, visto que nesse período se produziu um discurso racista com o intuito de justificar a prática escravista. Uma vez enraizado no imaginário social, esse discurso opera de maneira silenciosa em diferentes esferas de poder, obstaculizando a atuação e ascensão de homens e mulheres afrodescendentes, tolhendo-lhes o direito de respirar (p.3).

Para Ribeiro (2016), o racismo no Brasil é o crime perfeito, pois, ainda que promova a desigualdade, as pessoas continuam negando-o: "Mas é só ligar a tevê: os negros estão sempre em papéis estereotipados, bem específicos, nunca é uma pessoa comum. É a gostosa do samba, é a empregada, ou seja, ou é o lugar da subalternidade ou o lugar da exotização". (s/p).

Considerando a ideia anterior da atribuição forçada de um lugar de subalternidade ao negro, no poema Neguinho, Caldeira destaca as violências praticadas na época colonial como gérmen da desigualdade atual: “... a pele preta era sexo/ violência/ vibração/ pulsação/ seu corpo invadido pela dondoca e o patrão/ que arrancaram/ de uma só vez seu coração (p.12). Essas violências explicariam as razões do luto por um sistema que inferioriza seus semelhantes, como destacado no poema Luto: “(...) um sistema que sequer me reconhece/ na dura construção de um mundo sem mim/ sem gay/ sem preto/ sem pobre/ sem alimento/ sem educação/ os únicos cem que me sobram:/ cem tiros contra mim. (p. 26).

A referência dos 100 tiros faz menção às inúmeras brutalidades policiais em opera- ções nas periferias do Brasil. Desta forma, Karnal (2017), alerta para o genocídio da população negra, principalmente de jovens de 18 a 25 anos, que estão na mira desses “(...) navios negreiros em forma de viatura (190?, p.39)". Um problema constante e injustificável que envolve negligência política, máfia, narcotráfico e que seleciona cor de pele e gênero sexual de vidas que parecem que foram construídas para não importar; “(...) Um corpo composto/ Mas pro açoite/ Pro estado/ Era apenas um número." (Neguinho 2, p.35).

A contemporaneidade também está presente ao referir-se à situação do Brasil na pandemia do covid-2019: más decisões políticas que resultaram em mais de $500 \mathrm{mil}$ mortes; falta de insumos médicos, as incitações recorrentes à violência armada, o Brasil de volta ao mapa da fome, desemprego, desesperança, insatisfação e desânimo popular, como é notável no poema Ninguém:

(...) se leito não têm/ se máscara não vem/ É a invisibilidade de um sujeito/ que tem sua subjetividade não reconhecida/ mas abre a porta/ e a desigualdade escancara/ uma realidade genocida/ Estatística/ 0 manto que cobre o brasil que faz arminha/ é um manto de sangue/ condecorado num slogan:/ pátria armada, pátria mal caráter, brazil! (40-41).

Por outro lado, há uma exaltação à mestiçagem, à aceitação de suas origens e a busca de forças em sua ancestralidade para entender-se como sujeito negro no contexto em que vive e reagir, enfrentar, combater o seu entorno hostil:

eu não me sou escravo/ entretanto escrevo aqui/ em minhas tortas linhas/ o naufrágio da identidade que busco;/ do meu turbante,/ da minha língua,/ do meu cabelo,/ de meus patuás e/ da minha ancestralidade/ que passaram por entre atlânticos/ e ruminou/ uma ruptura do meu berço-mãe/ des- 
locado/ e alocado num tempo-banzo/ agora navego aqui/ dentro de mim/ escolhendo/ qual faceta/ colonial/ eu não vou mais vestir,/ e nem mais insistir/ em existir/ em um eu escravizado (Exportação, p. 44).

O orixá na capa, assim como os búzios, o obi, o ori, a saudação a Iansã, Epahey Oyá, o abebé de Oxum e o Egungu, são alguns dos inúmeros elementos da religiosidade africana no Brasil, com caraterística dos iorubás, do candomblé. Considerando essa ideia, é importante pensar como a transmissão e manutenção da cultura religiosa africana fortalece, dá sentido à vida e representam uma âncora, um pilar, um instrumento de sobrevivência para muitas comunidades negras no Brasil"1:

mamãe me mostrou no abebé/que nós somos filhos da mais pura água dos rios/ ela sorriu/ mostrou a beleza que tenho/ entre estrelas e vento/ dentro/carrego em mim todo amor desta vida/ diante de suas pedras/ ela me lava/ lava meu ori entre as correntezas/ e de lá/ escorrem minhas incertezas/ que se solidificam em amor e purezas/ ela me ensina/ a me amar/ e /a me completar/ como um perfeito príncipe nagô que sou (Abebé, p.25)

Há uma tentativa clara de representar o coletivo negro por meio da metáfora do mar; esse que trouxe o povo africano ao Brasil e com ele muita dor e resistência. Essa resistência que não permite o silenciamento do autor, como sugere o título do livro, mas sim, que represente seus irmãos, visibilizando experiências ora individuais, ora coletivas, já que são elementos de identificação para outros negros como ele. Esse mar que limpa as incertezas (p.25), cuja correnteza reben-

1 Aqui cabe citar o preconceito por parte de religiões ocidentais, como o protestantismo, que tem ameaçado a existência e permanência desse legado religioso, pois é comum o ataque aos terreiros e líderes dessas crenças. ta em versos (p.45) e que indica a fluidez do eu lírico do poeta que quer manifestar-se (p.32).

Tendo em vista o argumento mencionado, é possível recorrer ao neologismo de Conceição Evaristo, escrevivência, para evidenciar uma produção artística que nasce de suas vivências e experiências que expõem a condição do negro no Brasil. Ademais, é uma escrita que requer sobrevivência porque é difícil viver da literatura e projetar-se como poeta negro, enfatizando como esta condição exige o empoderamento do autor: "dentro da semente obi/ emerge/ é pura a tessitura do tempo que cura/ rebento /do odu nascido/ pra ser/ o que o/ infinito lhe couber (Rebento p. 21).

muitos me disseram/ que minha poesia/ tinha sabor em ser falada/ talvez vinda de um resquício/ de menino/ de sempre ser silenciada/ devolva-me a voz e o papel/ quero quebrar aquilo que jamais se ouviu/ como uma corrente/ que sempre/ aprisionou o 'nós' / e que por violência/ nos desumanizou/ e nos desuniu/ e que diante disso levanto minha voz e grito:/ Epahey Oyá, eu resisto. (Aprisionar p. 24)

Este grito de resistência "Epahey Oyá”, dialoga com a frase introdutória do livro, também de Evaristo: "Eles combinaram de nos matar, mas nós combinamos de não morrer". Pode ser entendido como um manifesto pelo direito à literatura, ao reconhecimento autoral, à legitimação do escritor negro no campo cultural brasileiro. À vista disso, Duarte (2011) nos convida a refletir sobre a necessidade de uma literatura afro -brasileira que complemente a literatura canônica ao visibilizar a expressão dos afrodescendentes como protagonistas de sua arte diante de uma sociedade que os exclui do mundo das letras ou, como sugere Santos e Pereira (2020), estabelecer uma forma de 
resistência que coloque “(..) em xeque velhas estruturas destinadas a manter e a sustentar a absurda ideia de que a raça humana não se mostra profundamente demarcada por uma diversidade que enseja o respeito e a dignidade de todos os seus integrantes". (p.4).

A modo de conclusão, é imprescindível deleitar-se mais nessa obra e descobrir outras possíveis análises que não couberam nesta discussão. Além disso, e pensando nas dificuldade que o autor teve para publicar seus poemas, fica o convite para participar de sua vaquinha virtual e contribuir para que Caldeira continue iluminando-nos com suas ideias ${ }^{2}$.

Epahey Oyá!

\section{Referências}

CALDEIRA, Bruno, Por mais fortes que possam ser os teus anseios, você não pode segurar a água. São Paulo: Artefato Edições, 2020.

CARDOSO, Paula. Racismo e censura incentivam araraquarense a lançar 1ํ livro. 2020. Disponívelem: <https://www.acidadeon.com/
araraquara/cotidiano/NOT, $0,0,1541076$,racismo $\% 20 \mathrm{e} \% 20$ censura $\% 20$ incentivam $\% 20$ araraquarense $\% 20 \mathrm{a} \% 20$ lancar $\% 201 \% 20$ livro. aspx>. Acesso em: 03 julho. 2021.

DUARTE, E. A. e FONSECA, M. N. S. (Org.) Literatura e afrodescendência no Brasil: antologia crítica. Belo Horizonte: Editora UFMG, 2011, vol. 4: História, teoria, polêmica.

KARNAL, Leandro. Todos contra todos: o ódio nosso de cada dia. Rio de Janeiro: Leya, 2017.

MACEDO, Fernanda. CABRAL, Magali. Racismo no Brasil: "O crime perfeito". Entrevista com Djamila Ribeiro. 2016. Disponível em: < https:// racismoambiental.net.br/2016/02/07/racismo-no-brasil-o-crime-perfeito-entrevista-com -djamila-ribeiro/>. Acesso em: 01 julho. 2021.

NASCIMENTO, Abdias. Axés do Sangue e da Esperança: Orikis. Rio de Janeiro: Achiamé. 1983, p.107.

SANTOS, Daiana Nascimento dos. PEREIRA, Édimo de Almeida. Eu não consigo respirar. VERBO DE MINAS, Juiz de Fora, v. 21, n. 37, p. 3-5, jan./ jun. 2020 - ISSN 1984-6959 - Qualis B1.

Recebido em: 07/07/2021

Aprovado em: 05/10/2021

cC) (i) Esta obra está licenciada com uma Licença Creative Commons Atribuição 4.0 Internacional.

2 https://benfeitoria.com/vcnpodeseguraragua 